\title{
A CERÂMICA CAMPANIENSE DO MONTE MOLIÃO, LAGOS. OS HÁBITOS DE CONSUMO NO LITORAL ALGARVIO DURANTE OS SÉCULOS II A.C. E I A.C. RECTIFICACIÓN
}

\author{
THE CAMPANIAN CERAMIC OF MONTE MOLIÃO, LAGOS. CONSUMPTION PATTERNS IN \\ ALGARVE COASTLINE DURING THE SECOND CENTURY BC AND THE FIRST BC. \\ CORRECTION
}

VANESSA DIAS*

Rectificación en el artículo Dias, V. (2015): A cerámica campaniense do Monte Moliâo, Lagos, os hábitos de consumo no litoral algarvio durante os séculos II a.C. e I a.C.”. Spal. Revista de Prehistoria y Arqueología 24: 99-128.

Vanessa Dias, autora del artículo “A cerámica campaniense do Monte Moliâo, Lagos, os hábitos de consumo no litoral algarvio durante os séculos II a.C. e I a.C.", publicado en el no 24 de la revista Spal. Revista de Prehistoria y Arqueología, nos comunica con fecha 3 de mayo de 2015 la existencia de un error en el citado texto. Atendiendo a la petición de la autora informamos que la figura 26 (página 119) es errónea, siendo sustituida por la que se presenta en la página siguiente

Vanessa Dias, autora do artigo "A cerámica campaniense do Monte Moliâo, Lagos, os hábitos de consumo no litoral algarvio durante os séculos II a.C. e I a.C.", publicado no $\mathrm{n}^{\circ} 24$ da Revista SPAL, Revista de Prehistoria y Arqueología, comunicou a 3 de maio de 2015 a
Correction at paper Dias, V. (2015): A cerámica campaniense do Monte Moliâo, Lagos, os hábitos de consumo no litoral algarvio durante os séculos II a.C. e I a.C.”. Spal. Revista de Prehistoria y Arqueología 24: 99-128.

existência de uma gralha no referido texto. Tendo em conta o pedido da autora, informamos que a figura 26 (página 119) está errada, e foi substituida pela que se apresenta na página seguinte.

Vanessa Dias, author of the paper "The campanian ceramic of Monte Molião, Lagos. Consumption Patterns in Algarve coastline during the second century BC and the first BC." published in number 24 of SPAL, Revista de Prehistoria y Arqueología. The author informs us (e-mail dated May 3, 2015) the existence of an error in that paper: figure 26 (page 119) must be replaced by the one shown below.

\footnotetext{
* Arqueóloga e Investigadora. Correo-e: vsitimadias@gmail.com
} 


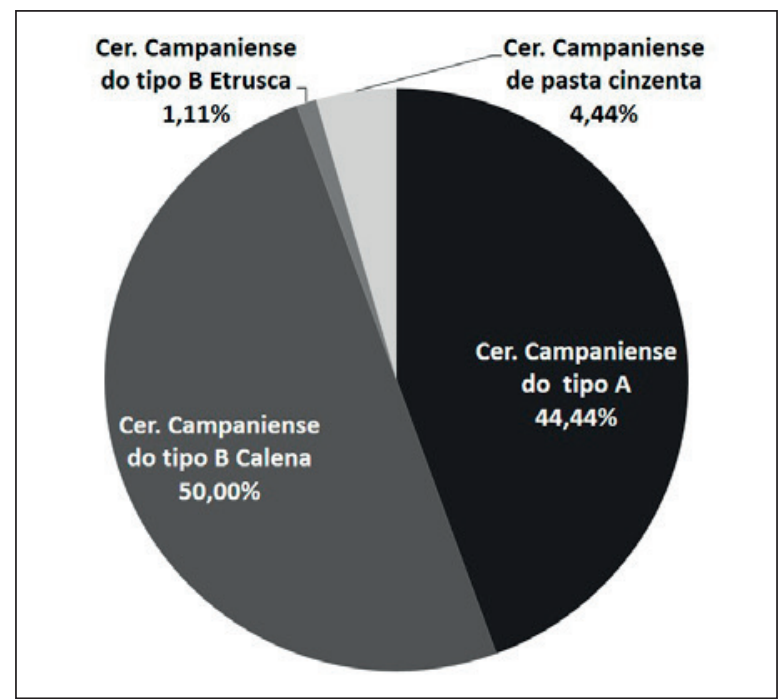

Figura 26. Cerâmica campaniense em contexto, na fase II do sector $\mathrm{C}(\mathrm{NMI})$. 